\title{
An Examination of History for Promoting Diversity in Neuroscience
}

\author{
M. Angele Theard ${ }^{1}$
}

Accepted: 9 June 2021 / Published online: 9 August 2021

(C) Springer Science+Business Media, LLC, part of Springer Nature 2021

\begin{abstract}
Purpose of Review A review of American history is presented to understand how public policy has contributed to a disproportionate burden of disease in members of underrepresented groups. A review of research conducted in the Stroke Belt provides an opportunity to examine more closely traditional and non-traditional risk factors in an effort to consider strategies for change. Recent Findings A diverse physician workforce has been offered as a way of improving care for our increasingly diverse populace. Given the expected increased prevalence of stroke in communities of color and the impact of stress from discrimination on health, proactive strategies to promote inclusion and equity to support diversity in perioperative neuroscience is warranted. Summary Public policy rooted in structural racism has left marginalized groups economically and educationally disadvantaged with less access to health care. Mistrust and fear from ongoing discrimination compels the neuroscience community to broaden their approach for developing a more reassuring and supportive educational environment for patients and trainees.
\end{abstract}

Keywords Diversity $\cdot$ Perioperative care $\cdot$ Health disparities $\cdot$ Neuroscience $\cdot$ Anesthesiology $\cdot$ Education

\section{Introduction}

In 1890, at the age of 70, Harriet Tubman, the architect behind the Underground Railroad, underwent "awake brain surgery" at Massachusetts General Hospital. She hoped to relieve herself of the achin' in her head which appears to have plagued her most of her life (1). Whether narcolepsy, cataplexy, and seizures, afflictions attributed to Ms. Tubman were coincident to or a consequence of head trauma suffered as a young child at the hands of the slave overseer, is unclear (1-3). Trephination for head injury was performed at Massachusetts General in the 1800s, and the first anesthetic was conducted there in $1846(4,5)$. So why did Harriet Tubman wait until 1890 to have neurosurgery for what appears to have been a long life of suffering? Historically in the USA, access to treatment was limited for the enslaved. Laws prohibiting reading and literacy among African Americans precluded awareness of scientific and clinical advancements. The dehumanization of African Americans supported by the

This article is part of the Topical Collection on Topical Collection on Neuroanesthesia

M. Angele Theard

theard@ohsu.edu

1 Department of Anesthesiology, Oregon Health \& Science University, Portland, OR, USA institution of slavery appropriated this group for medical experimentation, assuring a rift from the medical establishment (6•*). Over one hundred years later, limited educational opportunities precluding health literacy and economic stability; mistrust of the medical establishment; and bias in health care promotes continued limited access to care for members of underrepresented groups (URG) $(7 \bullet \bullet, 8 \bullet \bullet)$. People of color compared to Whites in the USA disproportionately experience illness and death in almost every category of medicine including stroke (Fig. 1) (9-11•). Stroke associated with poor health, perioperative stroke, and trauma potentially affecting both young and older members of our populace is expected to become more prevalent by $2030(12,13 \cdot, 14-16)$. This is particularly concerning in African American communities where stroke is already more prevalent. Moreover, the mounting evidence of the ability of SARS-CoV-2 to infiltrate the central nervous system and the disproportionate infection rate and mortality from this virus in Black and Brown communities compels continued innovative research as well as effective strategies for transforming our medical system $(17,18)$. As our medical institutions focus on promoting equity and inclusion in medicine, the neuroscience community has an opportunity to help broaden initiatives focused on reducing these disparities. This review will focus on stroke in African American communities in the USA in order to understand the factors contributing to health disparities and the role of inclusion and equity in promoting constructive change. 


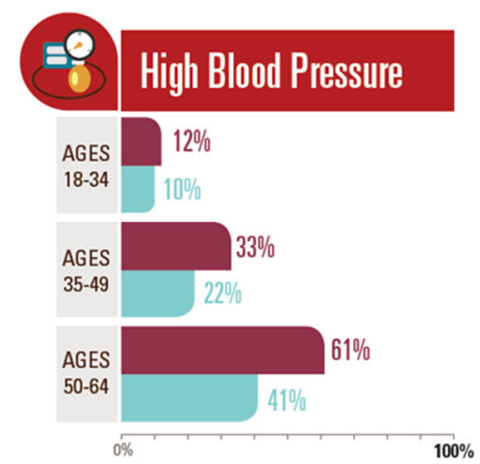

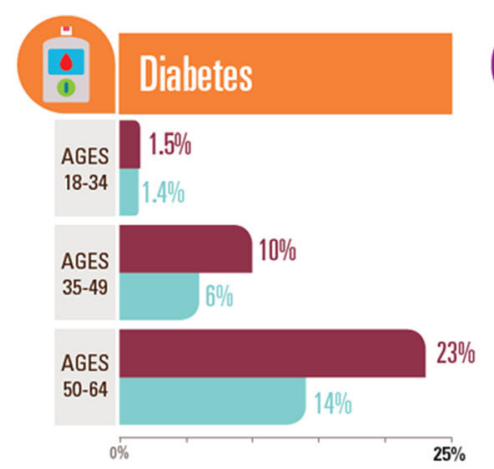

African Americans and whites include Hispanic and non-Hispanic origin.

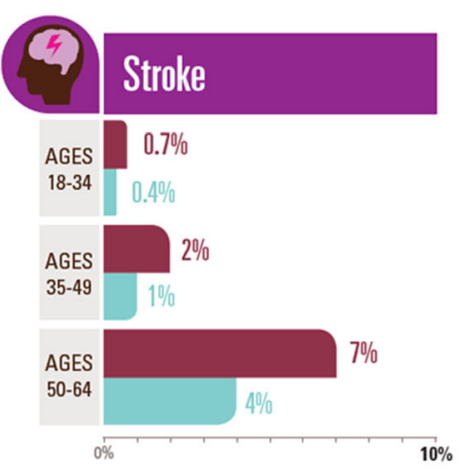

SOURCE: Behavioral Risk Factor Surveillance System, 2015.
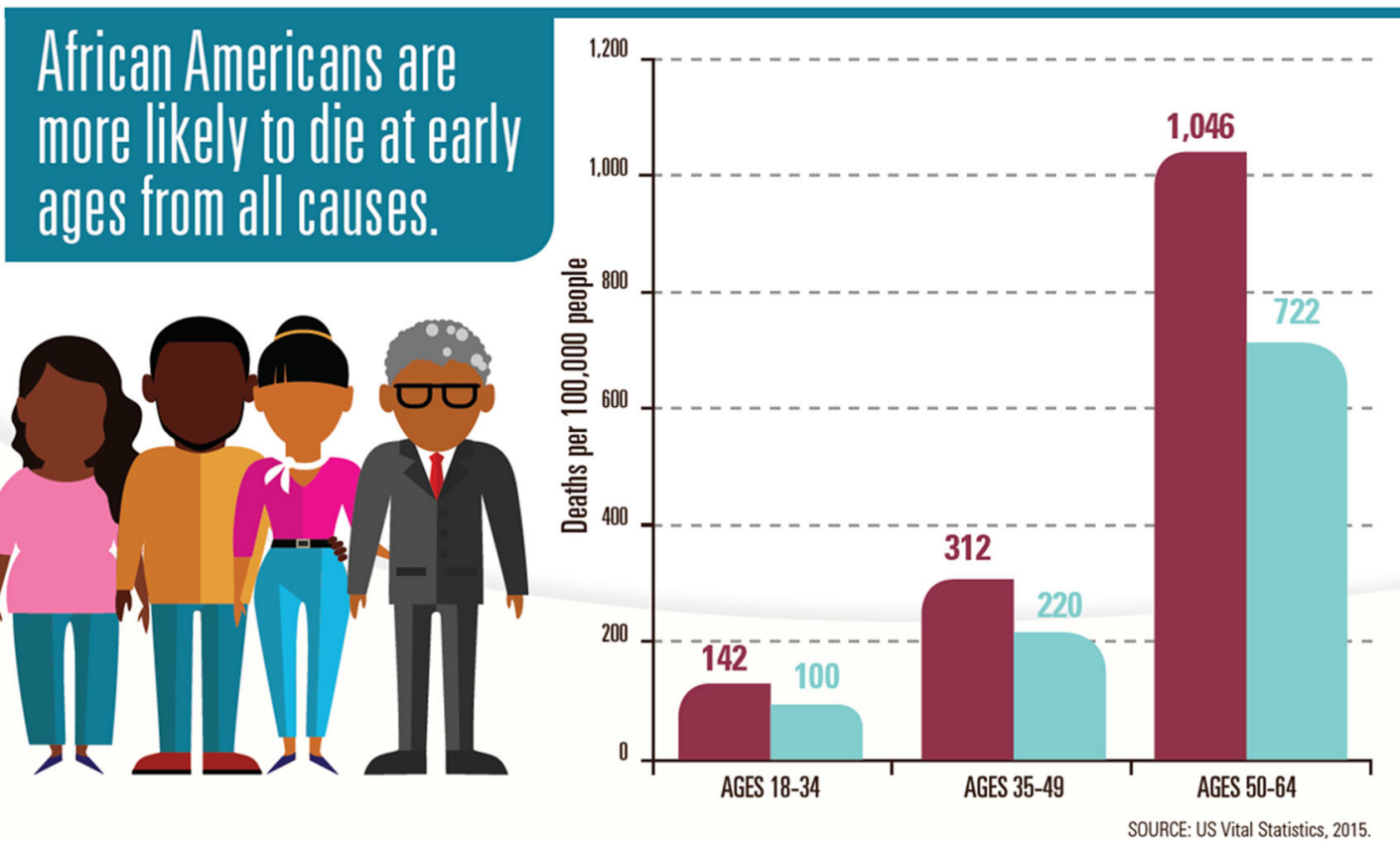

Fig. 1 Disparities in health, https://www.cdc.gov/vitalsigns/aahealth/index.html\#anchor_1490282293. Not subject to copyright permission

While considerable research is available on stroke in African Americans, this discussion also pertains to many equally underrepresented groups in our society today.

\section{Search Strategy}

A literature search was conducted in PubMed from 2010 to 2020. A literature review was performed using the following search terms: risk factors for stroke; outcomes and sequelae after stroke; African Americans and stroke risk; stroke belt; surgical/neurosurgical outcomes in African Americans; neurological outcomes and COVID-19; bias in health care; social determinants of health and stroke; education and health; health literacy and health; smoking and stroke; psychosocial determinants of health; stress and racial discrimination in disease; medical education and discrimination; allostatic load; syndemics of disease; and diversity in medical education. A second literature search was conducted in Academia for scholarly reviews on the history of structural racism in the USA and its impact on health disparities. A literature search of this database was performed using some of the aforementioned search terms in addition to the following: structural racism and public policy; diversity in medicine; structural racism in medicine; and stress and discrimination. Additional references in notable review articles were also included in this search. Additionally, the centers for disease control (CDC), US census, US Vital statistics, Association of American medical Colleges (AAMC), Accreditation Council for graduate Medical Education (ACGME), the Behavioral Risk Factors Surveillance System, and the American Public Health Association websites were searched for data regarding housing, health, education, and medical insurance in different ethnic/racial groups. 
The Burden of Neurological Disease in African Americans

Stroke is one of the more prevalent neurological disorders affecting nearly 100 million Americans (14). A systemic analysis in the 2017 Global Burden of Disease study revealed that the absolute number of people affected between 1990 and 2017 by non-communicable neurological disorders had increased, with stroke, TBI, and Alzheimer's disease (AD) in the top five. The two leading causes of mortality were AD and stroke. Additionally, stroke was the second leading cause of disability-adjusted life-years. Seventy-three percent of stroke survivors fall within 6 months of their stroke and these patients are four times more likely to break their hip necessitating surgery associated with an increased risk for perioperative stroke (19). Equally concerning is that of the 795,000 stroke events occurring annually in the USA, African Americans are represented at a rate two times Whites (20-22). Moreover, African Americans and Hispanics who make up 13.4\% and $18.5 \%$ of the US population, respectively, suffer from stroke at a younger age compared to Whites $(23 \bullet, 24)$. Renewed efforts to eliminate racial disparities prompted by evidence of the disproportionate number of URGs infected and dead from COVID-19 compel a more comprehensive understanding of stroke risk in African Americans (25-27).

\section{The Stroke Belt for Understanding Stroke Risk in African Americans}

Research from the National Heart, Lung, and Blood Institute (NHLB) noted a 10\% increase in stroke mortality in a cluster of states in the southeastern part of the USA compared to the rest of the country. They identified 11 states as the stroke belt: Alabama, Arkansas, Georgia, Indiana, Kentucky, Louisiana, Mississippi, North Carolina, South Carolina, Tennessee, and Virginia (see Fig. 2) $(28 \bullet \bullet, 29)$. A small subset within this region termed the stroke buckle (North Carolina, South Carolina, and Georgia) was notable for a $40 \%$ higher stroke mortality. The Reasons for Geographic and Racial Differences in Stroke (REGARDS) study was a longitudinal populationbased cohort study of over 29,000 participants designed to investigate factors associated with high stroke mortality among residents of the stroke belt $(30 \cdot 31,32)$. The highest rate of stroke was in the stroke buckle $(614 / 100,000$ personyears), followed by the stroke belt $(547 / 100,000$ personyears), with the lowest rate of stroke in the non-stroke belt (517/100,000 person-years). The highest Black-White sex-adjusted incidence ratio rate (IRR) was for the youngest age group, $45-54$ years $(4.02$; $95 \%$ CI, $1.23-13.11)$. Racial differences in traditional risk factors (atrial fibrillation, DM, increased systolic blood pressure, heart disease, smoking, $\mathrm{LVH}$ ) and socioeconomic status (education level) accounted for $53 \%$ of the Black excess stroke incidence in the $45-65$ year age range. Systolic hypertension (average in Blacks with strokes $139 \pm 18.3$ ), use of anti-hypertensive agents, and a history of diabetes (glucose $\geq 126 \mathrm{mg} / \mathrm{dL}$ ) were the largest contributing factors. In an earlier study examining reasons for the increased stroke in the stroke belt in over $27,000 \mathrm{pa}-$ tients, the authors determined that race/ethnicity was responsible for $20 \%$ of the excess stroke risk. Differences in socioeconomic status (educational attainment and income) and chronic disease each contributed $32 \%$ to stroke risk for a total contribution of just over $80 \%$ (32). In addition to poorly controlled hypertension common among African Americans, other reasons offered for the unaccounted increased risk included disparities in non-traditional factors like diet and physical inactivity; psychosocial factors like anger and depression; and lack of awareness $(33,34)$. A broad-based discussion of the social determinants of health in the African American community is helpful in understanding the influence of some of these factors on stroke risk.

\section{The Social Determinants of Health}

According to the American Public Health Association, the social determinants of health refer to "nonmedical factors" like income, employment, education, housing, neighborhood conditions, systemic racism, and discrimination (35••). In the USA, approximately $80 \%$ of health disparities occur in $16 \%$ of the 38,000 zip codes (36). Tobacco, alcohol, obesity, blood pressure, and cholesterol are some of the most proximal modifiable factors accounting for adverse health outcomes in the USA and disparities across race-ethnicity and geographical groups. Economic stability (income and employment) is a clear cornerstone of the social determinants of health as this factor assures a future of generational wealth facilitated by economically advantaged neighborhoods $(37,38,39 \bullet \bullet)$. The link between socioeconomics and health is clear. According to the US census bureau, as of 2018, poverty rates for Blacks (20.8\%) and Hispanics (17.6\%) were higher compared to Whites $(8.1 \%)(40)$. Inequities in health insurance are also evident. Hispanics $(53.5 \%)$ and Blacks $(56.5 \%)$ lag behind Whites $(72.2 \%)$ in the rate of private health insurance, and both Hispanics (39.5\%) and Blacks (44.1\%) are more likely to have government health insurance compared to Whites (36.6\%) (40). Limited acceptance of Medicaid; reliance on emergency room care; and care at hospitals which have a two-tiered system whereby care is provided to private patients by faculty with residents assigned to patents with Medicaid or no insurance impact the continuity of care and influence outcomes $(40,41,42,43)$. An examination of the history of structural racism as a root cause of the economic disparity underlying the limitations of African Americans success in achieving the social determinants of health is a necessary first 
Fig. 2 Stroke Belt, National Institute of Health, National Heart Lung and Blood Institute28. Not subject to copyright permission

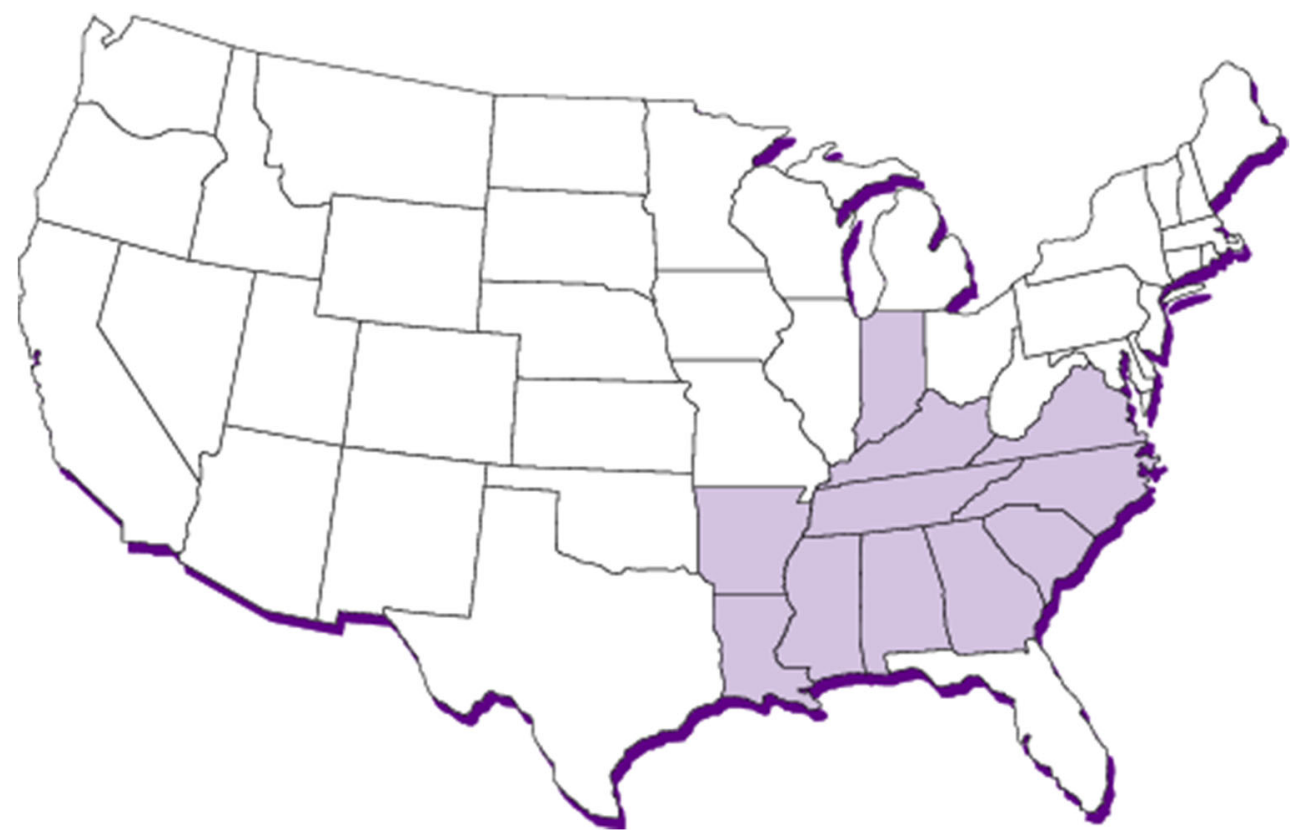

step in developing a more compressive approach to patient care, education, and research in neuroscience.

\section{History of Structural Racism and Public Policy}

A history of discriminatory laws and public policy like de jure segregation (legalized segregation) encouraged practices which would economically disadvantage African Americans for years to come. These laws were founded upon institutional racism, a construct of American thought, which began 400 years ago. America's near elimination of Native Americans and the enslavement of Africans served as the precedent for institutionalized racism - a confluence of institutions, culture, history, ideology, and codified practices that generate and perpetuate inequity among racial and ethnic groups $(38,43,44 \cdot \bullet)$. Public policies like redlining and restrictive housing covenants; exclusion from programs designed for promoting wealth like the GI bill; and the social security act of 1935 superimposed on a history of disenfranchisement served to bar African Americans from achieving wealth and future economic stability $(38,39 \bullet \cdot)$. Discriminatory public policies like redlining, a term used to describe the denial of financial services to residents of a certain racial or ethnic group, were a common strategy for denying African Americans access to certain "White" neighborhoods. Directly, through denial of a mortgage or indirectly by offering prohibitively high interest loans, these practices would supplant real estate agents' support of restrictive housing covenants designed to prohibit Black people from living in White neighborhoods. The GI Bill of 1944, adopted to support returning service men provided mortgage subsidies and stipends to cover college tuition. However, service men with dishonorable discharges, for reasons like protesting segregation in army towns, were ineligible for benefits under this bill. Veterans that were eligible, due to the aforementioned discriminatory housing practices, were effectively excluded. Additionally, opportunities for secondary education were limited due to ineffective early educational experiences. The Social Security Act of 1935 provided financial support for the elderly and unemployment compensation. However, this act, which excluded agricultural workers and domestic servants, left out African Americans who were more likely to hold these types of jobs. These policies and practices founded on systemic racism directed African Americans to poor, educationally disadvantaged neighborhoods, low-income jobs, and more of the same for generations to come.

\section{The Impact}

The impact of these policies and practices are substantial. American cities continue to be largely segregated $(44 \bullet, 45-47 \bullet)$. A lack of investment in segregated communities of color is responsible for the lack of efficacy in neighborhood schools. Weak curricula, a dearth of counseling, and unqualified teachers assure limited educational and financial success for future generations which necessarily affects health $(44 \bullet, 45,46,48)$. People with lower education levels demonstrate lower literacy skills when compared to people with higher levels of education, and this translates to medication non-compliance, deficiency in preventative health care strategies, and increased mortality $(45,46,48,49 \bullet \bullet, 50 \bullet)$. A segregated America also promotes isolation of marginalized groups 
from a lifestyle, which supports successful achievement of many of the social determinants of health $(45,51 \bullet \bullet$. In a study examining the association between fast food restaurant density and Black and low-income neighborhoods in New Orleans, LA, predominantly Black neighborhoods had 2.4 fast-food restaurants per square mile compared to 1.5 fast food restaurants in predominantly White neighborhoods (52). These neighborhoods also known as food desserts promote obesity implicated in the development of hypertension and cardiovascular disease which is increasing in the USA particularly in Black communities. Superimposed upon poor diets are habits like smoking, which contributes to heart disease and stroke. Interestingly, despite a similar smoking prevalence, more advertising efforts target African American communities compared to Whites by a factor of about 2:1 $(52,53)$. The limited success of efforts to reduce health disparities through initiatives like federal funding to increase Black and Brown student representation in education, waning affirmative action policies, and diversity and inclusion programming requires a deeper probe into less notable factors like anger and stress from discrimination. A defined educational level achieved used to explain health disparities may not accurately characterize educational experiences, i.e., bullying in a particular grade or lack of efficacy in vocational school may not produce the expected results $(35 \cdot \bullet, 43)$. The need for a more holistic approach to addressing the multidimensional aspects of the impact of structural racism in our communities of color will necessarily compel us to move beyond the more proximate risk factors for surgical outcomes like stroke. Broader consideration of the impact of the experiences of our patients on their physical and emotional health may help direct us toward the development of more effective strategies for improving outcomes.

\section{The Syndemic Theory of Health}

The syndemic model of health compels a more mindful consideration of the impact of discrimination and bias on disease. Syndemic theory originally used to understand and address the AIDS epidemic considers the aggregation of two or more diseases or other health or social conditions in which there is a deleterious biological or behavioral interface that exacerbates the negative health effects of any or all diseases involved (55). According to the syndemic theory of health, the legacy of structural racism that produces mistrust, fear, and bias contributes to negative health outcomes typically under conditions of health inequality. In the case of stroke, this approach to medicine takes into account for example the associated stress and anxiety from mistrust and discrimination from racism to understand the disproportionate prevalence of diseases like hypertension and stroke in African Americans $(6 \bullet \bullet, 55)$

\section{Experimentation and Trust}

Medical experimentation and abuse of African Americans was common during slavery: from repeated surgery on Black woman without anesthesia in order to understand treatment options for ureterovaginal fistulas to denial of available treatment for syphilis in Black men to better characterize neurological complications from syphilis $(6 \cdot \bullet)$. This history has contributed to African American mistrust of the medical establishment promoting hesitancy in seeking care. A survey conducted for National Public Radio, the Robert Wood Johnson Foundation, and Harvard TH Chan School of Public Health in 2017 revealed a majority of African Americans reporting having personally experienced racial slurs and people making negative assumptions about their race (56•). Additionally, higher income Black Americans were more likely to report experiences of discrimination. In regard to medical care, $32 \%$ reported that they were discriminated against when going to the doctor and $22 \%$ avoided medical care even when in need for fear of discrimination. Mistrust compounded by fear of discrimination in African Americans limits access to care in patients who are economically advantaged, and in those with lower incomes, poor health outcomes are potentially exacerbated.

\section{Implicit Bias}

Implicit bias defined as unconscious or involuntary attitudes that lie below the surface of consciousness influences behavior and cognitive processes (57). These automatic perceptions of reality are born out of received information and experiences, which over time become programmed into thinking (57). In terms of race, the literature has identified implicit pro-White bias occurring as early as age $3(58 \cdot, 59-62)$. Efficient decision-making helpful for physicians under time pressures for diagnosis and treatment may enable racial bias from reinforced stereotypes based on race to compromise care of members of marginalized groups. According to the Institute of Medicine's report Unequal treatment: confronting racial and ethnic disparities, which examined reasons for the lower quality of health care in ethnic minorities, stereotyping and bias appeared to play a role (7•). In a review of 15 studies examining implicit bias measured using the Implicit Association Test (IAT) in health care workers, most had some level of implicit bias (positive attitudes toward Whites and negative attitudes toward people of color $\left(57,63^{\circ}\right)$. In a study examining the factors mediating the relationship between patient race/ethnicity and provider recommendations for CABG surgery, a mostly White physician cohort rated Blacks as noncompliant with medical therapy and laziness (64). These perceptions were significant predictors of their treatment recommendations independent of clinical factors, appropriateness, 
and payer and physician characteristics. A literature review conducted to examine the role of implicit bias in health care disparities revealed an association between higher implicit bias and care disparities (vignette-based studies) in type II diabetes mellitus follow-up, pain management in children, and empathy in counseling (65-67). In one real life study examining outcomes (function and well-being), spinal cord injury patients cared for by physicians with high IAT scores (high pro-White/anti-Black bias) had lower social integration, greater depression, and lower life satisfaction (68). Negative perceptions felt by African Americans like poorer communication or the feeling that they would receive better care and more respect from medical staff if they belonged to another racial group undoubtedly affect follow-up (69•, 70, 71). Perceptions held by Blacks as well as other marginalized patients while difficult to quantify might be a key determinant affecting the disproportionate burden of disease in these groups. While changing the mindsets of African Americans may be an important aspect of reducing health disparities, anger and stress from ongoing discrimination also have biological consequences $(43,72 \bullet)$

\section{Emotional and Physiologic Chronic Stress}

Evidence of African Americans experiencing a greater response to racist stimulation in films and the relationship between stress-related cardiovascular reactivity and increased blood pressure serves as the precedent for examining the link between perceived discrimination and hypertension $(72 \bullet, 73)$. Associations between increased experiences of racial discrimination and/or high resilience scores with increased blood pressure in African Americans may reflect the body's limited ability to cope $(74,75)$. Allostasis defined as "maintaining stability through change"-for example, in the cardiovascular system - characterizes the role of catecholamines in facilitating adjustments in heart rate (HR) and blood pressure (BP) during physical exertion or a good stress which results in growth and development $75,76 \bullet \bullet, 77 \bullet$. However, continued unabated stress leads to allostatic load-_wear and tear" on the body from chronic elevation of catecholamines - which in turn leads to chronic increases in HR and BP affecting organ systems leading to diseases like stroke. The higher systolic blood pressure among working class Black women who internalized experiences of discrimination compared to groups who challenged unfair treatment in a cohort of Black men and women from the Coronary Artery Risk Development in Young Adults Study (CADIA) may be a reflection of the progression to allostatic load consequent to the repeatedly ignored encounters of racism $(72 \bullet, 73,74)$. Understanding this model of responses to stress requires appreciation of features like individual differences in coping based on genetics and experiential factors, and that allostasis has a price or allostatic load which the body pays for being forced to adapt to psychological challenges and adverse environments (75, 76••, 77•). Enhanced food intake, for example, to replenish energy reserves in response to adrenal steroids, promotes allostasis; however, the over activity of this system in stress leads to excess cortisol accelerating the progression of abdominal obesity. Using a national nutritional health survey, allostatic load scores (based on 10 biomarkers defined in previous studies which include systolic blood pressure, diastolic blood pressure, body mass index, glycated hemoglobin, albumin, creatinine clearance, C-reactive protein, cholesterol, homocysteine, and triglycerides) in Black adults were higher than in Whites. Additionally, Blacks experienced earlier deterioration of health in response to life in a race-conscious society (78). This so-called weathering - the experience of Blacks who undergo health deterioration due to the cumulative impact of repeated experiences of social adversity and political marginalization - may contribute to earlier physical aging and deterioration. The perioperative neuroscience physician well-versed in the relevance of preoperative anxiety in the surgical patient is well-suited to integrate this body of science into their practice to better understand and serve our patients (79). Moreover, our experience in building successful multidisciplinary chronic pain clinics and awake craniotomy programs focused on individualized approaches to care affords us an opportunity to provide valuable input in eliminating disparities. Success in addressing the needs of African Americans and members of other marginalized groups will also require inculcating a diverse group of providers: nurses, physician assistants, pharmacists, physicians, scientists, and educators into these spaces.

\section{Needed Support for Diverse Patients and Trainees}

The Institute of Medicine, National Medical Association, Association of American Medical Colleges, and the American Medical Association have all suggested a more diverse health care profession for addressing health disparities $(7,80-82)$. The Oakland study identified Black patient/doctor concordance for reducing the Black-White male gap in cardiovascular mortality by $19 \%$ (83). The innovative Barbershop study builds on this proposal with evidence linking a potentially more suitable learning environment for improving health among African Americans (84••). In a study addressing hypertension in Black men (barbershop patrons) with baseline $\mathrm{SBP} \geq 140$, barbershops were assigned to either a pharmacist-led intervention (in which barbers encouraged meetings with specialty-trained pharmacists who prescribed drug therapy under a practice agreement with participant's doctors) or to an active control group (in which barbers encouraged lifestyle medication and doctor appointments). At 6 
months, health promotion by barbers coupled with medication management played a role in significantly reducing SBP in the intervention group: $63.3 \%$ of participants in the intervention group had $\mathrm{BP}<130 / 80 \mathrm{vs} 11.7 \%$ of participants in the control group $(\mathrm{p}<0.001)$. Convenience (pharmacists made drug therapy available at the barbershop); barbers - trusted community members; and the participant - a loyal patron — were reasons provided for the observed benefit. Additionally, $40 \%$ of the participants (mostly low-income Black males) did not have a doctor to sign the practice agreement; therefore, one main community physician served as their supervising doctor. Feelings of familiarity, comfort, and trust (the barbershop) may have helped to secure a more favorable atmosphere for learning together with better access leading to better blood pressure control.

Welcoming the next generation of medical students who are today becoming educationally equipped to move beyond disease-focused approaches to understanding health disparities will also require a reassuring educational millieu $(85$, 86•). Data from the AAMC for 2018/19 indicate that the number of Latino-Hispanic (6\%) African American (7\%) and American Indian/Alaska natives $(0.2 \%)$ remains low compared to Whites (58\%) (87). In a review of the literature on the learning environments experienced by underrepresented in medicine (UriM), less positive learning environments, racial harassment, and discrimination were associated with poorer academic performance and higher attrition rates $(88 \bullet \bullet)$. In a survey of over 7000 surgical residents in the USA, $16.6 \%$ experienced racial discrimination and feelings of burnout with $4.5 \%$ of these residents experiencing suicidal ideations (89॰). Additionally, AAMC data revealed that in anesthesiology, internal medicine, pediatrics, and surgery, there was a significantly higher dismissal rate among Black residents compared to White residents (90). In addition to the impact of physician burnout on the quality of patient care, these experiences elude our success in attracting needed African Americans to medicine (91). Attention to promoting a supportive learning environment for trainees of color is a necessary step in promoting their educational success in all areas of medicine including neuroscience.

\section{Conclusion}

This past year, calamitous occurrences in our society like the disproportionate deaths due to COVID-19 and law enforcement in Black and Brown communities has exposed the continuing problem of systemic racism increasingly identified as a cause of our current public health crises $(92,93)$. A call to the medical community to participate in helping to remedy this disproportionate burden of disease in communities of color requires an understanding of the root causes of this consequential problem presented in this review. Harriet Tubman's resilience and that of fellow enslaved Africans helped them to survive a horrendous epoch in America with the hope that future generations would thrive. Her innovative and resourceful approach for guiding so many enslaved to freedom despite a chronic, debilitating neurological condition is a testament to the human capacity to adapt despite unquestioned allostatic load that should have precluded Ms. Tubman's life extending past 90. While the burgeoning field of epigenetics will help to elucidate this phenomenon, eliminating systemic racism to help unburden members of URGs of a disparate disease load is long overdue (94). The field of neuroscience affords us an appreciation of the brain's capacity for change in an effort to accommodate our ever-changing internal and external needs (95). Eliminating disparities in care due to bias and stress from discrimination and swaying members of URGs away from commonly held mistrust and fear will necessarily require mindful transformation of our health care workforce. Thoughtful faculty development programs; a supportive learning environment for trainee members of underrepresented groups; and a broader more inclusive approach to neuroscience research supported by a strong administration are necessary for eradicating the isolation and bias of systemic racism $\left(96^{\circ}\right)$ (Table 1 ).

A nationwide analysis from the National Inpatient Sample (NIS) of nine surgical procedures, including carotid endarterectomy performed in Black and White patients in 2017 revealed higher surgical use by Whites compared to Blacks (97). Efforts to increase surgical procedure use by African Americans provide our medical establishment an opportunity for collaborative change.

Neuroscientific discovery for optimizing neurologic outcomes will benefit from neuroscience team members with differing perspectives and skill sets $(98,99)$. The SHARP program (Sharing history through active reminiscence and Photo-imagery) for increasing physical, social, and cognitive activity within a culturally meaningful context to support cognitive wellness for African Americans, and research which encompasses more holistic healing-centered engagement are opportunities for prehabilitation and healing in Black and Brown communities (100••).

Our impending physician shortfall provides yet another opportunity to reduce disparities by promoting a more diverse health care workface. Results of a recent survey of trainees and faculty, identified areas to focus on to increase interest in needed neuroanesthesia fellowship training to support increasingly complex neuroanesthetic care (101). Promoting the benefits of fellowship training and the acquisition of new skill sets in an environment, which respects and appreciates differences, provides an opportunity to welcome and retain underrepresented trainees in medicine $(92,96 \bullet)$. Educationally transformed clinicians, educators, mentors, researchers, scientific reviewers, and editors will help to support an inclusive and equitable environment in medicine enriching the minds of all members of our specialty and improving the care of all of our patients. 
Table 1. Interventions for educational programs, faculty educators, researchers, and clinicians

$\begin{array}{llll}\text { Goals } & \text { Evaluation/reflection } & \text { Knowledge/learning }\end{array}$

\section{Education}

- Educational curriculum which includes tools for addressing racism and discrimination in the learning environment

- Understanding the health impact of systemic racism

- Supportive educational environment for URiM

- Evaluate program

- Understand available resources and

\section{Faculty 96•}

- Diverse health care workforce

- Change in educators' behaviors, perspectives, assumptions, and unintentional biases

- Skill sets for "learning how to dialogue about race and racism"-for meaningful and transformative conversation between learner and faculty

\section{Research}

- Shift to multidisciplinary approach incorporating historical, political, social, economic, cultural, and racial perspectives into research

- Expand participants of color and age range for this group 80

- Broaden research groups (diverse groups) and endorse grant funding which supports research in diversity and disparity-related research

\section{Administration}

- Funding support

- Equity and inclusion leaders, and educational specialists

- Hire/promotion of ethnic/racially diverse faculty/candidates

- Mentoring and sponsorship of new hires

\section{Clinicians}

- Understanding and addressing patient preoperative concerns

- Prehabilitation program incl. health literacy, physical, and emotional health

- Awareness of diversity/lack of diversity in practice environment

\section{- Understand faculty members' perspectives, comfort and ability to discuss race, identity, culture, and discrimination for informing a faculty development program}

- Education and self-reflection on systemic racism, social determinants of health, and educational theory (trainees/patients/nursing/hosp. staff) bias and its impact qualitatively (surveys) and quantitatively (IAT)

- Understand goals and needs of learner, faculty, and institution solutions (educational specialists)
- Gain insight from other programs

- Learn conceptual frameworks to guide a more standardized curriculum, teaching, and clear assessments

- Relationship building with faculty and trainees

- Identify promising approaches used in other fields for combating racism.

- Experienced facilitators for educational programing

- Provide earned professional certification on DEI
- Ongoing quantitative

- Ongoing qualitative (small focus groups) to assess program

- Impact on learning environment (resident satisfaction surveys, performance, retention)

- Ongoing qualitative (small focus groups) to assess program

- Satisfaction, awareness of implicit bias, able to use critical pedagogy

- Use data to improve outcomes and effect faculty/workforce changes

- Exploration of self and self in relation to others - how cultural background influences how I experience the world and interact with those of research participants
- Learn racial and cultural beliefs and experiences of people and communities being examined

- Learn from community partners
- Collaboration meetings and or focus groups including diverse public health expertise to interpret data

- Share perspectives on data interpretations
- Assessment of department membership/at all levels, i.e., thoughts regarding inclusion and equity

\section{- Ongoing assessment: recruitment, retention, satisfaction}

\begin{tabular}{|c|c|c|}
\hline $\begin{array}{l}\text { - Exploration of self and self in relation to } \\
\text { patients ... how cultural background } \\
\text { influences how I experience the world } \\
\text { and interact with those of the patients }\end{array}$ & $\begin{array}{l}\text { - Understand racial and } \\
\text { cultural beliefs and } \\
\text { experiences of } \\
\text { patients/families } \\
\text { - Develop community } \\
\text { partnerships for } \\
\text { engagement regarding } \\
\text { preoperative preparation }\end{array}$ & $\begin{array}{l}\text { - Patient outcomes } \\
\text { - Community relationships } \\
\text { - Retention, satisfaction, and } \\
\text { growth of physicians of all } \\
\text { backgrounds }\end{array}$ \\
\hline
\end{tabular}

Acknowledgements The author wishes to thank Thabiti Lewis, $\mathrm{PhD}$, for his review and advice regarding the sections related to the history of structural racism in America and Rebecca Harrison, MD, for her review and insight regarding faculty development for promoting educational success among trainees.

\section{Compliance with Ethical Standards}

Conflict of Interest The author does not have any potential conflicts of interest to disclose. 
Human and Animal Rights and Informed Consent This article does not contain any studies with human or animal subjects performed by any of the authors.

\section{References}

Papers of particular interest, published recently, have been highlighted as:

- Of importance

-• Of major importance

1. Bradford SH Harriet, The Moses of her people. 1886. USA, Monee, Illinois

2. Bassetti C, Aldrich MS. Narcolepsy. Neurol Clin. 1996 Aug;14(3):545-71. https://doi.org/10.1016/s0733-8619(05) 70273-5.

3. Bassetti CLA, Adamantidis A, Burdakov D, Han F, Gay S, Kallweit U, et al. Narcolepsy-clinical spectrum, aetiopathophysiology, diagnosis and treatment. Nat Rev Neurol. 2019;15:519-39. https://doi.org/10.1038/s41582-019-0226-9.

4. Barker FG. The Massachusetts General Hospital, early history and neurosurgery to 1939. J Neurosurg. 1993;79:948-59.

5. Haridas RP. "Gentlemen! This is No Humbug" Did John Colllins Warren, MD., Proclaim these words on October 16, 1846, at Massachusetts General Hospital, Boston? Anesthesiology. 2016;124:553-60.

6.• Washington H Medical apartheid: the dark history of experimentation on Black Americans from colonial times to the present. 2007, Doubleday, ISBN978-0385509930 A well-written review of the history of medical experimentation upon African Americans.

7.• Smedley BD, Stith AY, Nelson AR, et al. Institute of Medicine. In: Unequal treatment: confronting racial and ethnic disparities in health care. Washington, DC: The National Academies Press; 2003. https://doi.org/10.17226/12875 Provides comprehensive coverage of literature necessary for understanding health disparities.

8.• Williams RA. Blacks in medicine: clinical, demographic, and socioeconomic correlations. Switzerland AG: Springer Nature; 2020. https://doi.org/10.1007/978-3-030-41960-8 Provides comprehensive coverage of literature necessary for understanding health disparities.

9. National Center for Health Statistics. Health, United States, 2018. Hyattsville, MD. 2019 . https://www.cdc.gov/nchs/ data/hus/hus18.pdf

10. Semega J, Kollar M, Creamer J, Mohanty A. U.S. Census Bureau, Current Population Reports, P60-266(RV). In: Income and poverty in the United States: 2018. Washington, DC: U.S. Government Printing Office; 2020.

11. Haider AH, Scott VK, Rehman KA, Velopulos C, Bentley JM, Cornwell EE 3rd, et al. Racial disparities in surgical care and outcomes in the United States: a comprehensive review of patient, provider, and systemic factors. J Am Coll Surg. 2013;216(3):48292.e12. https://doi.org/10.1016/j.jamcollsurg.2012.11.014 Provides comprehensive information on the state of health of underrepresented groups in the US.

12. Fox CK, Hills NK, Vinson DR, et al. Population-based study of ischemic stroke after trauma in children and young adults. Neurology. 2017;89:2301-16.

13. Disparities in neurological care: time to act on inequities, editorial https://www.thelancet.com/pdfs/journals/laneur/PIIS1474- 4422(20)30211-8.pdf Provides comprehensive information on the state of health of underrepresented groups in the US.

14. GBD. 2017 US Neurological Disorders Collaborators. Burden of neurological disorders across the US From 1990-2017: a global burden of disease study. JAMA Neurol. 2021;78(2):165-76. https://doi.org/10.1001/jamaneurol.2020.4152.

15. Mashour GA, Woodrum DT, Avidan MS. Neurological complications of surgery and anaesthesia. BJA: Br J Anaesth. 2015;114(2):194-203. https://doi.org/10.1093/bja/aeu296.

16. Lindberg AP, Flexman AM. Perioperative stroke after non-cardiac, non-neurological surgery. BJA Educ. 2021;21(2):59-65. https://doi.org/10.1016/j.bjae.2020.09.003.

17. Jha NK, Ojha S, Jha SK, et al. Evidence of Coronavirus $(\mathrm{CoV})$ pathogenesis and emerging pathogen SARS-CoV-2 in the nervous system: a review on neurological impairment and manifestations. J Mol Neurosci. 2021. https://doi.org/10. 1007/s12031-020-01767-6.

18. Flexman A, Abcejo AS, Avitsian R. Neuroanesthesia Practice during the COVID-19 pandemic: recommendations from the society of for neuroscience in anesthesiology and critical care (SNACC). JNA. 2020;32:202-9.

19. Duncan PW, Bushnell C, Sissine M, et al. Comprehensive stroke care and outcomes. Stroke. 2021;52:385-93. https://doi.org/10. 1161/STROKEAHA.120.029678.

20. Stroke facts. National Center for Chronic Disease Prevention and Health Promotion, Division for Heart Disease and Stroke Prevention https://www.cdc.gov/stroke/facts.htm

21. Kissela B, Schneider A, Kleindorfer D, Khoury J, Miller R, Alwell $\mathrm{K}$, et al. Stroke in a biracial population: the excess burden of stroke among blacks. Stroke. 2004;35(2):426-31. https://doi.org/10. 1161/01.STR.0000110982.74967.39.

22. Sacco RL, Boden-Albala B, Gan R, et al. Stroke incidence among White, Black and Hispanic residents of an urban community the Northern Manhattan stroke study. Am J Epidemiol. 1998;147(3): 259-68. https://doi.org/10.1093/oxfordjournals.aje.a009445.

23. Burke JF, Feng C, Skolarus LE. Divergent poststroke outcomes for black patients Lower mortality, but greater disability. Neurology. 2019;93(18):e1664-74. https://doi.org/10.1212/ WNL.0000000000008391 Provides comprehensive information on the state of health of underrepresented groups in the US.

24. United States Census 2015/2019., assessed Feb. 2021 https:// www.census.gov/quickfacts/fact/table/US/RHI225219

25. Sze S, Pan D, Nevill CR, et al. Ethnicity and clinical outcomes in COVID-19: a systemic review and meta-analysis. EclinicalMedicine, 2020. 2020;29-30. https://doi.org/10.1016/j. eclinm.2020.100630.

26. Ross J, Diaz CM, Starrels JL. The disproportionate burden of COVID-19 for immigrants in the Bronx, New York. JAMA Intern Med. 2020;180(8):1043-4. https://doi.org/10.1001/ jamainternmed.2020.2131.

27. Karaca-Mandic P, Georgiou A, Sen S. Assessment of COVID-19 hospitalizations by race/ethnicity in 12 states. JAMA Intern Med. 2021;181(1):131-4. https://doi.org/10.1001/jamainternmed.2020. 3857.

28.• Hafner RR, Bland S, Hager B, et al. Stroke belt initiative, National Institutes of Health, National Heart, Lung, and Blood Institute.1996 https://www.nhlbi.nih.gov/files/docs/resources/ heart/sb_spec.pdf Provides comprehensive coverage of literature necessary for understanding health disparities.

29. Lanska DJ, Kuller LH. The geography of stroke mortality in the United States and the concept of a stroke belt. Stroke. 1995;26:1145-9.

30. Howard G, Cushman M, Kissela B, et al. Traditional risk factors as the underlying cause of racial disparities in stroke: lessons from the half full (empty?) glass. Stroke. 2011;42(12):3369-75 
Provides comprehensive information on the state of health of underrepresented groups in the US.

31. Howard G, Anderson R, Johnson NJ. et al. Evaluation of social status as a contributing factor to the stroke belt region of the United States. 1997;28:936-940

32. Howard VJ, Do K, Judd SE, et al. Disparities in stroke incidence contributing to disparities in stroke mortality. Ann Neurol. 2011;69:619-27.

33. Liao Y, Greenlund KJ, Croft JB, Keenan NL, Giles WH. Factors explaining excess stroke prevalence in the US Stroke Belt. Stroke. 2009 Oct;40(10):3336-41. https://doi.org/10.1161/ STROKEAHA.109.561688.

34. Fryar CD, Ostchega Y, Hales CM, Zhang G, Kruszon-Moran D. Hypertension prevalence and control among adults: United States, 2015-2016. NCHS Data Brief. 2017;289:1-8.

35.• Howard G, Moy CS, Howard VJ, et al. REGARDS Investigators. Where to focus efforts to reduce the Black-White disparity in stroke mortality: incidence versus case fatality? Stroke. 2016;47(7):1893-8. https://doi.org/10.1161/STROKEAHA.115. 012631 Provides comprehensive coverage of literature necessary for understanding health disparities.

36. Puckrein GA, Egan BM, Howard G. Social and medical determinants of cardiometabolic health: the big picture. Ethn Dis. 2015:4, 521-25, 524. https://doi.org/10.18865/ed.25.4.521.

37. Murray CJ, Kulkarni S, Ezzati M. Eight Americas: new perspective on US health disparities. Am J Prev Med. 2005;29(5S1):4-10.

38. Rosen G. A History of public health. Md: JHU press; 1993.

39.• Rothstein R. The color of law: a forgotten history of how our government segregated America. NY: Liveright Pub.(W.W.Norton Co.); 2017 Provides comprehensive coverage of literature necessary for understanding health disparities.

40. Semega J., Kollar M, Creamer J. Income and poverty in the United States: 2018. Current Population Report https://www.census.gov/ content/dam/Census/library/publications/2019/demo/p60-266.pdf

41. Gorelick PB. Cerebrovascular disease in African Americans. Stroke. 1998;29(12):2656-64.

42. Saadi A, Himmelstein DU, Woolhandler S, Mejia NI. Racial disparities in neurologic health care access and utilization in the United States. Neurology. 2017;88(24):2268-75. https://doi.org/ 10.1212/WNL.0000000000004025.

43. Pandey DK, Gorelick PB. Epidemiology of stroke in African Americans and Hispanic Americans. Med Clin N Am. 2005;89(4):739-52. https://doi.org/10.1016/j.mena.2005.02.005.

44.•• Bailey ZD, Krieger N, Agénor M, Graves J, Linos N, Bassett MT. Structural racism and health inequities in the USA: evidence and interventions. Lancet. 2017;389(10077):1453-63. https://doi.org/ 10.1016/S0140-6736(17)30569-X Provides comprehensive coverage of literature necessary for understanding health disparities.

45. Schulz AJ, Williams DR, Israel BA, Lempert LB. Racial and spatial relations at fundamental determinants of health in Detroit. Milbank Quarterly. 2002;80(4):677-707.

46. Williams DR, Collins C. Racial residential segregation: a fundamental cause of racial disparities in health. Public Health Rep. 2001;116:404-16.

47. Williams DR. Race, socioeconomic status, and health. The added effects of racism and discrimination. Ann N Y Acad Sci. 1999;896:173-88. https://doi.org/10.1111/j.1749-6632.1999. tb08114.x.

48. Massey DS, Tannen J. A research note on trends in Black hypersegregation. Demography. 2015;52(3):1025-34 www.jstor.org/stable/43699174.

49.• Cohen AK, Syme AL. Education: A missed opportunity for public health intervention. Am J Public Health. 2013;103(6):997-1001.
50. The Lancet Public Health. Education: a neglected social determinant of health. Lancet Public Health. 2020;5(7):e361. https://doi. org/10.1016/S2468-2667(20)30144-4 Provides comprehensive coverage of literature necessary for understanding health disparities.

51.• Mantwill S, Monestel-Umaña S, Schulz PJ. The relationship between health literacy and health disparities: a systematic review. PLoS One. 2015;10(12):e0145455. https://doi.org/10.1371/ journal.pone.0145455 Provides comprehensive coverage of literature necessary for understanding health disparities.

52. Block JP, Scribner RA, DeSalvo KB. Fast food, race/ethnicity, and income. Am J Prev Med. 2004;27(3):211-217 50.

53. Shah RS, Cole JW. Smoking and stroke: the more you smoke the more you stroke. Expert Rev Cardiovasc Ther. 2010;8(7):917-32. https://doi.org/10.1586/erc.10.56.

54. Alaniz ML. Alcohol availability and targeted advertising in racial/ ethnic minority communities. Alcohol Health Res World. 1998;22(4):286-9.

55. Singer M, Bulled N, Ostrach B, et al. Syndemics and the biosocial conception of health. Lancet. 2017;389:10072.

56. Discrimination in American: Final Summary, 2017. Assessed, Feb. 2021. https://cdn1.sph.harvard.edu/wp-content/uploads/ Provides comprehensive information on the state of health of underrepresented groups in the US.

57. Maina IW, Belton TD, Ginzberg S, Singh A, Johnson TJ. A decade of studying implicit racial/ethnic bias in healthcare providers using the implicit association test. Soc Sci Med. 2018 Feb;199: 219-29. https://doi.org/10.1016/j.socscimed.2017.05.009.

58. Chapman EN, Kaatz A, Carnes M. Physicians and implicit bias: how doctors may unwittingly perpetuate health care disparities. J Gen Intern Med. 2013;28(11):1504-10. https://doi.org/10.1007/ s11606-013-2441-1 Provides comprehensive information on the state of health of underrepresented groups in the US.

59. Bigler RS, Liben LS. A developmental intergroup theory of social stereotypes and prejudice. Adv Child Dev Behav. 2006;34:39-89. https://doi.org/10.1016/s0065-2407(06)80004-2.

60. Newheiser AK, Olson KR. White and Black American children's implicit intergroup bias. J Exp Soc Psychol. 2012;48(1):264-70. https://doi.org/10.1016/j.jesp.2011.08.011.

61. Dunham Y, Baron AS, Banaji MR. From American city to Japanese village: a cross-cultural investigation of implicit race attitudes. Child Dev. 2006;77(5):1268-81. https://doi.org/10. 1111/j.1467-8624.2006.00933.x.

62. Baron AS, Banaji MR. The development of implicit attitudes: evidence of race evaluations from ages 6 and 10 and adulthood. Psychol Sci. 2006 Jan;17(1):53-8. https://doi.org/10.1111/j.14679280.2005.01664.x.

63. Hall WJ, Chapman MV, Lee KM, Merino YM, Thomas TW, Payne BK, et al. Implicit racial/ethnic bias among health care professionals and its influence on health care outcomes: a systematic review. Am J Public Health. 2015;105(12):e60-76. https:// doi.org/10.2105/AJPH.2015.302903 Provides comprehensive information on the state of health of underrepresented groups in the US.

64. Van Ryn M, Burgess D, Malat J, Griffin J. Physicians' perceptions of patients' social and behavioral characteristics and race disparities in treatment recommendations for men with coronary artery disease. Am J Public Health. 2006;96(2):351-7. https://doi.org/ 10.2105/AJPH.2004.041806.

65. Charles LT, 2009. Causal and predictive relationships among race, implicit racial bias, and simulated treatment recommendations (Doctoral dissertation), Retrieved from ProQuest Dissertations \& Theses Global: The Sciences and Engineering Collection. (Publication No. 3380481).

66. Sabin JA, Greenwald AG. The influence of implicit bias on treatment recommendations for 4 common pediatric conditions: pain, 
urinary tract infection, attention deficit hyperactivity disorder, and asthma. Am J Public Health. 2012;102(5):988-95. https://doi.org/ 10.2105/AJPH.2011.300621.

67. Katz AD, Hoyt WT. The influence of multicultural counseling competence and anti-Black prejudice on therapists' outcome expectances. J Couns Psychol. 2014;61(2):299-305. https://doi.org/ 10.1037/a0036134.

68. Hausmann LRM, Myaskovsky L, Niyonkuru C, Oyster ML, Switzer GE, Burkitt KH, et al. Examining implicit bias of physicians who care for individuals with spinal cord injury: a pilot study and future directions. J Spinal Cord Med. 2015;38(1):102-10. https://doi.org/10.1179/2045772313Y.0000000184.

69. Cooper LA, Roter DL, Carson KA, Beach MC, Sabin JA, Greenwald AG, et al. The associations of clinicians' implicit attitudes about race with medical visit communication and patient ratings of interpersonal care. Am J Public Health. 2012;102(5): 979-87. https://doi.org/10.2105/AJPH.2011.300558 Provides comprehensive information on the state of health of underrepresented groups in the US.

70. Penner LA, Dovidio JF, West TV, Gaertner SL, Albrecht TL, Dailey RK, et al. Aversive racism and medical interactions with Black patients: a field study. J Exp Soc Psychol. 2010;46(2):43640. https://doi.org/10.1016/j.jesp.2009.11.004.

71. Johnson RL, Saha S, Arbelaez JJ, Beach MC, Cooper LA. Racial and ethnic differences in patient perceptions of bias and cultural competence in health care. J Gen Intern Med. 2004;19(2):101-10. https://doi.org/10.1111/j.1525-1497.2004.30262.x.

72. Krieger N, Sidney S. Racial discrimination and blood pressure: the CARDIA Study of young black and white adults. Am J Public Health. 1996;86(10):1370-8. https://doi.org/10.2105/ajph.86.10. 1370 Provides comprehensive information on the state of health of underrepresented groups in the US.

73. Treiber FA, Kamarck T, Schneiderman N, et al. Cardiovascular reactivity and development of preclinical and clinical disease states. Psychosom Med. 2003;65(1):46-62.

74. Vidal C, Polo R, Alvarez K, Falgas-Bague I, Wang Y, Lê Cook B, et al. Co-Occurrence of posttraumatic stress disorder and cardiovascular disease among ethnic/racial groups in the United States. Psychosom Med. 2018;80(7):680-8. https://doi.org/10.1097/ PSY.0000000000000601.

75. Krantz DS, Manuck SB. Acute psychophysiologic reactivity and risk of cardiovascular disease: a review and methodologic critique. Psychol Bull. 1984;96:435-64. https://doi.org/10.1037/00332909.96.3.435.

76.• McEwen BS. In pursuit of resilience: stress, epigenetics, and brain plasticity. Ann N Y Acad Sci. 2016;1373:56-64 Provides comprehensive coverage of literature necessary for understanding health disparities.

77. McEwen BS, Seeman T. Protective and damaging effects of mediators of stress: elaborating and testing the concepts of allostasis and allostatic load. Ann N Y Acad Sci. 1999;896:30-47. https:// doi.org/10.1111/j.1749-6632.1999.tb08103.x Provides comprehensive information on the state of health of underrepresented groups in the US.

78. Geronimus AT, Hicken M, Keene D. "Weathering" and age patterns of allostatic load scores among blacks and whites in the United States. Am J Public Health. 2006;96(5):826-31.

79. Perks A, Chakravarti S, Manninen P. Preoperative anxiety in neurosurgical patients. JNA. 2009;21(2):127-30. https://doi.org/10. 1097/ANA.0b013e31819a6ca3.

80. Association of American Medical Colleges. Addressing racial disparities in health care: a targeted action plan for academic medical centers. Washington, DC: AAMC; 2009.

81. National Medical Association. 2018. "Major minority physician associations come together." https://www.nmanet.org/news/
398042/Major-Minority-Physician-Associations-Come-Together. htm (accessed Feb 2021)

82. American Medical Association (AMA). 2018. "Reducing disparities in health care." https://www.ama-assn.org/delivering-care/ reducing-disparities-health-care (accessed Feb 2021)

83. Alsan M, Garrick O, Graziani G. Does diversity matter for health? Experimental evidence from Oakland. Am Econ Rev. 2019;109(12):4071-11. https://doi.org/10.1257/aer.20181446.

84.• Victor RG, Lynch K, Li N, et al. A cluster-randomized trial of blood-pressure reduction in black barbershops. NEJM. 2018;378: 1291-301. https://doi.org/10.1056/NEJMoa17250 Provides comprehensive coverage of literature necessary for understanding health disparities.

85. Gallegos, A. Medical schools tackle health care disparities through unique partnerships, Research AAMCNews 2017. https://www. aamc.org/news-insights/medical-schools-tackle-health-caredisparities-through-unique-partnerships-research assessed, Feb 2021

86. Diaz T, Navarro JR, Chen EH. An institutional approach to fostering inclusion and addressing racial bias: implications for diversity in academic medicine. Teach Learn Med. 2020;30(1):110-6. https://doi.org/10.1080/10401334.2019.1670665 Provides comprehensive information on the state of health of underrepresented groups in the US.

87. AAMC, 2019 applicant and matriculant data, assessed, 2020, Tables present data regarding medical school applicants and matriculants. https://www.aamc.org/data-reports/students-residents/ interactive-data/2019-facts-applicants-andmatriculants-data

88.• Orom H, Semalulu T, Underwood W. The social and learning environments experienced by underrepresented minority medical students: a narrative review. Acad Med. 2013;88:1765-77. https:// doi.org/10.1097/ACM.0b013e3182a7a3af Provides comprehensive coverage of literature necessary for understanding health disparities.

89. Hu Y-Y, Ellis RJ, Brock Hewitt D, et al. Discrimination, abuse, harassment, and burnout in surgical residency training. NEJM. 2019;381:1741-52. https://doi.org/10.1056/NEJMMsa1903759 Provides comprehensive information on the state of health of underrepresented groups in the US.

90. McDade, W. Diversity and inclusion in graduate medical education. (from Chief Diversity officer ACGME), $2018 \mathrm{http} / /$ southernhospitalmedicine.org/wp-content/uploads/2019/10/ McDade-ACGME-SHM-Presentation-McDade-Final.pdf Provides comprehensive information on the state of health of underrepresented groups in the US.

91. Dewa CS, Loong D, Bonato S, Trojanowski L. The relationship between physician burnout and quality of healthcare in terms of safety and acceptability: a systematic review. BMJ Open. 2017;7: e015141. https://doi.org/10.1136/bmjopen-2016-015141.

92. Devakumar D, Selvarajah S, Shannon G, Muraya K, Lasoye S, Corona S, et al. Racism, the public health crises we can no longer ignore. Lancet. 2020;395:e112-3. https://doi.org/10.1016/S01406736(20)31371-4.

93. Théard M, Lewis T. Stop the pandemic of racism. In: The Common Reader. St. Louis MO: Washington University; 2020. https://commonreader.wustl.edu/c/stop-the-pandemic-of-racism/.

94. Wallack L, Thornburg K. Development origins, epigenetics, and equity: moving upstream. Matern Child Health J. 2016;20:93540. https://doi.org/10.1007/s10995-016-1970-8.

95. Doidge N. The brain that changes itself. USA: Viking Penguin, a division of Penguin; 2007.

96. Karani R, Varpio L, May W, Horsley T, Chenault J, Miller KH, et al. Commentary: racism and bias in health professions education: how educators, faculty developers, and researchers can make a difference. Acad Med. 2017;92:S1-6. https://doi.org/10.1097/ ACM.0000000000001928 Provides comprehensive 
information on the state of health of underrepresented groups in the US.

97. Best MJ, McFarland EG, Thakkar SC, Srikumaran U. Racial disparities in the use of surgical procedures in the US. JAMA Surg. Published online January. 2021;13:274-81. https://doi.org/10. 1001/jamasurg.2020.6257.

98. Meyers VA. Moving diversity forward: how to go from wellmeaning to well-doing. In: Center for Racial and Ethnic Diversity. USA: American Bar Association; 2011.

99. Theard M, Flexman A, Smith M. Diversity, inclusion and equity in the Journal of Neurosurgical Anesthesiology: a look to the future. J Neurosurg Anesthesiol. 2020;32(4):283-4. https://doi. org/10.1097/ANA.0000000000000711.
100.• Croff RL, Witter P, Walker ML. Things are changing so fast: integrative technology for preserving cognitive health and community history. The Gerontologist. 2019;59(1):147-57. https:// doi.org/10.1093/geront/gny069 Provides comprehensive coverage of literature necessary for understanding health disparities.

101. Rajan S, Theard M, Easdown J, et al. Perceived benefits and barriers to a career in neuroanesthesiology: a pilot survey of anesthesiology clinicians. JNA. 2021;23(2):167-71.

Publisher's Note Springer Nature remains neutral with regard to jurisdictional claims in published maps and institutional affiliations. 